\title{
Role of Self-Concept and Self-Handicapping in Eating Disorders - Structural Model
}

\author{
Fatemeh Amini Seyyed ${ }^{1}$, Mohammad Moosavi, ${ }^{2, *}$ \\ ${ }^{1}$ Department of Psychology, Islamic Azad University of Sari, Sari, Iran \\ ${ }^{2}$ Department of Psychiatry, Mazandaran University of Medical Sciences, Sari, Iran
}

Email address:

mmosavi@mazums.ac.ir (M. Moosavi)

${ }^{*}$ Corresponding author

\section{To cite this article:}

Fatemeh Amini Seyyed, Mohammad Moosavi. Role of Self-Concept and Self-Handicapping in Eating Disorders - Structural Model. European Journal of Preventive Medicine. Vol. 6, No. 1, 2018, pp. 13-16. doi: 10.11648/j.ejpm.20180601.13

Received: December 2, 2017; Accepted: December 18, 2017; Published: January 19, 2018

\begin{abstract}
Current study aimed to offer structural model regarding role of Self-Concept and Self-Handicapping in eating disorder. Looking at high trend of morbidity and mushrooming number of eating disorder in clinical and non-clinical settings and its antagonistic features among afflicted individuals, and with respect to clinical implication and, theoretical dimensions, conducting current study seemed inevitable. Materials and Methods: This study was descriptive-correlational study. Statistical society of current study consisted of 750 individuals with BMI $\geq 25$, who were admitted to nutrition clinic at Sari General Hospital (Sari, Iran). Sample size was specified as 226 according to Krejcie and Morgan Table. We used Beck Self-Concept Test (BSCT) with respect to assessing self-concept, SHS with respect to self-handicapping assessment, EDDS (Eating disorder diagnostic scale) regarding assessment of eating disorders (anorexia nervosa, bulimia nervosa and binge eating disorder). With respect to data analyze, SPSS-22 and structural equation modeling and regression model via Lisrel test were used. Results: According to results of current study, self-concept and self-handicapping pose positive and influential roles with respect to anorexia nervosa, bulimia nervosa and binge eating disorder. Conclusion: Eating disorders are one of the leading causes of disturbance especially among women. Various factors are involved in pathogenesis of this disorder. In current study we delineated structural model with respect to Self-Concept and Self-Handicapping and eating disorders.
\end{abstract}

Keywords: Anorexia Nervosa, Bulimia Nervosa, Binge Eating Disorder, Self-Concept, Self-Handicapping

\section{Introduction}

Eating disorders are leading cause of somatic and psychosocial morbidity among adolescent girls and young adult women; morbidity number is much less frequent in men. Eating disorders are divided into three diagnostic categories: anorexia nervosa, bulimia nervosa, and the atypical eating disorders [1].

\subsection{Treatments and Therapies}

Adequate nutrition, reducing excessive exercise, and stopping purging behaviors are the foundations of treatment. Treatment plans are tailored to individual needs and may include one or more of the following:

1) Individual, group, and/or family psychotherapy

2) Medical care and monitoring
3) Nutritional counseling

4) Medications

\subsection{Psychotherapies}

Psychotherapy approaches such as a family-based therapy called the Maudsley approach, where parents of adolescents with anorexia nervosa assume responsibility for feeding their child, appear to be very effective in helping people gain weight and improve eating habits and moods. To reduce or eliminate binge-eating and purging behaviors, people may undergo cognitive behavioral therapy (CBT), which is another type of psychotherapy that helps a person learn how to identify distorted or unhelpful thinking patterns and recognize and change inaccurate beliefs [20].

Eating disorders, which are associated with a web of debilitating medical morbidities, negative psychological 
problems, and considerable reductions in quality of life, should be diagnosed and treated punctually. Nonetheless, primary care physicians may find it extremely devastating to diagnose eating disorders in their early stages, before obvious physical problems arise and while psychological symptoms are subtle [2]. Whereas numbers of recognized risk factors contributing to the development of eating disorders are increasing, previous evidence for biological, psychological, developmental, and sociocultural effects on the development of eating disorders have not been convincing. Despite the fact that a huge body of research has cautiously scrutinized the possible risk factors associated with the eating disorders, they have failed not only to uncover the exact etiology of eating disorders, but also to understand the interaction between different causes of eating disorders. This failure may be due complexities of eating disorders, limitations of the studies or combination of two factors [4-10]. In a similar endeavor with current study we assessed Role of Anxiety, Depression and Anger in Eating Disorders and we concluded that anxiety, depression and aggression maintain positive and influential roles with respect to anorexia nervosa, bulimia nervosa and binge eating disorder and accordingly proposed structural model [11]. In current study we aim to look at role of Role of Self-Concept and Self-Handicapping in Eating Disorders.

\section{Materials and Methods}

Current study was descriptive-correlational study. Statistical society of current study, consisted of 750 individuals with $\mathrm{BMI} \geq 25$, who were admitted to nutrition clinic at Sari General Hospital (Sari, Iran). Sample size was specified as 226 according to Krejcie and Morgan Table. We used BSCT with respect to assessing self-concept, SHS with respect to self-handicapping assessment, EDDS (Eating disorder diagnostic scale) regarding assessment of eating disorders (anorexia nervosa, bulimia nervosa and binge eating disorder). We analyzed obtained data via SPSS-22, structural equation modeling, regression model and Lisrel test.

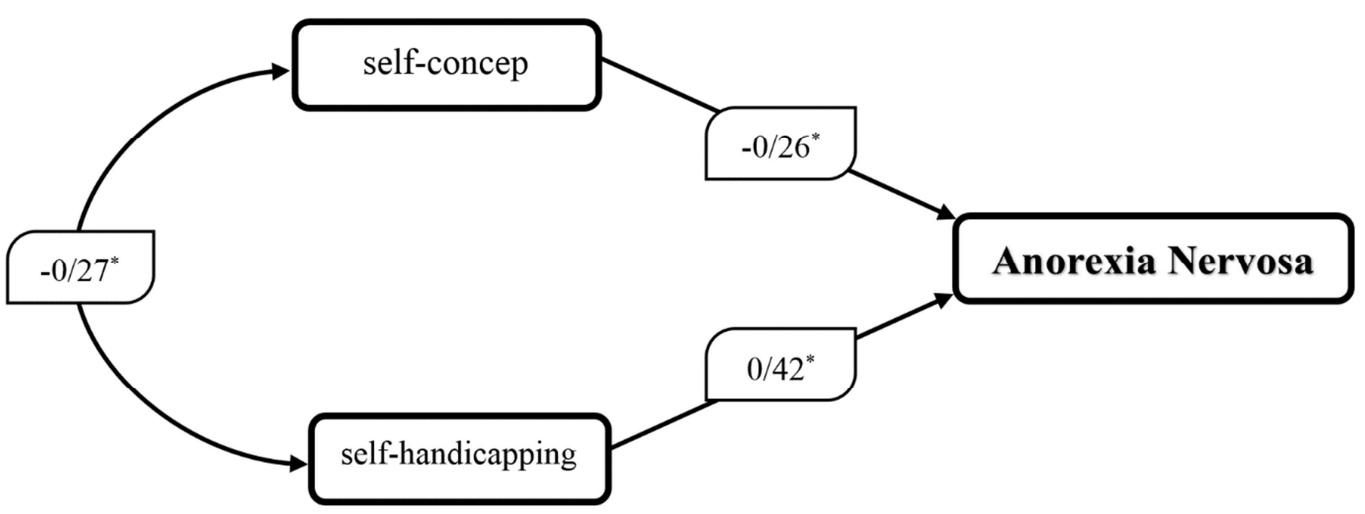

Figure 1. Analyzing Dynamic of Self-Concept, Self-Handicapping with Respect to Anorexia Nervosa.

Figure 1, illustrates relationship of Self-Concept and Self-Handicapping with respect to pathogenesis of AN.

According to results of current study, as predicted Self-Concept and Self-Handicapping play substantial role regarding pathogenesis of Bulimia Nervosa.

\subsection{The Eating Disorder Diagnostic Scale (EDDS)}

EDDS is a 22 item self-report questionnaire that assesses the presence of three eating disorders; anorexia nervosa, bulimia nervosa and binge eating disorder. It was adapted by Stice et al. in 2000 from the validated structured psychiatric interview: The Eating Disorder Examination (EDE) and the eating disorder module of the Structured Clinical Interview for DSM-IV (SCID) [12]. In follow up studies of the reliability and validity of the EDDS it was shown to be sufficiently sensitive to detect the effects of eating disorders prevention programs, response to such programs and the future onset of eating disorder pathology and depression. The EDDS shows both full and sub threshold diagnoses for anorexia nervosa, bulimia nervosa and binge eating disorder. EDDS is a continuous eating disorder symptom composite score [13]. The PhenX Toolkit uses the EDDS for as an Eating Disorders Screener protocol [14].

\subsection{Beck Self-Concept Test (BSCT)}

This questionnaire was firstly adapted by Beck. It is consisted of 25 questions with 5 likert scale. Participant compares himself with others and accordingly he answer to questions [15].

\subsection{Self-Handicapping Scale (SHS)}

This questionnaire contains 25 questions with 0-6 likert scale [16].

Obtained data from aforementioned questionnaires was accordingly assessed via SPSS-22, structural equation modeling, regression model and Lisrel test.

\section{Results}

According to results of current study, as predicted SelfConcept and Self-Handicapping play substantial role regarding pathogenesis of Anorexia Nervosa. 


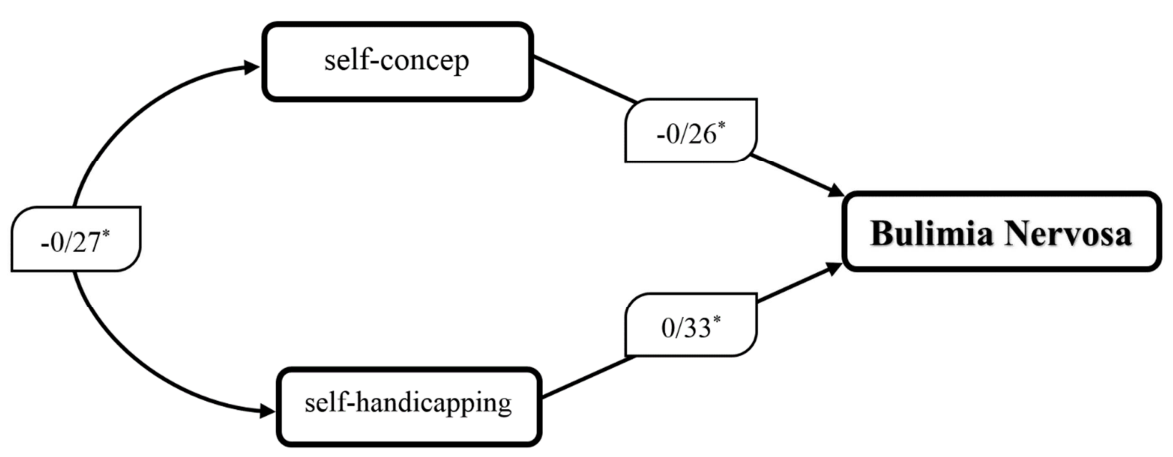

Figure 2. Analyzing Dynamic of Self-Concept and Self-Handicapping with Respect to Bulimia Nervosa.

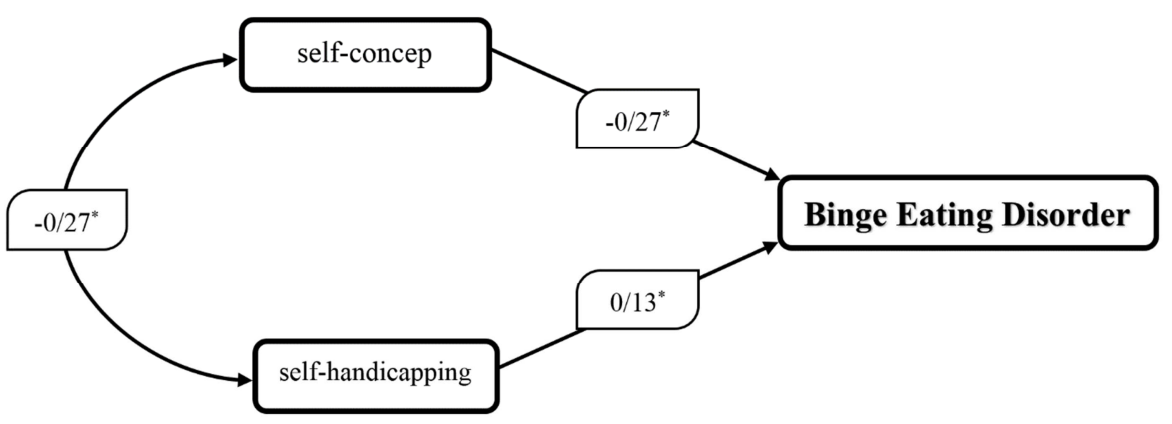

Figure 3. Analyzing Dynamic of Self-Concept and Self-Handicapping with respect to Binge Eating Disorder.

Figure 2, delineates relationship of Self-Concept and SelfHandicapping with respect to pathogenesis of AN. According to results of current study, as predicted Self-Concept and Self-Handicapping maintain decisive role regarding pathogenesis of BN. According to Figure 3, Self-Concept and Self-Handicapping maintain influential role with respect to pathogenesis of BEA.

\section{Discussion}

There is a widely held perspective that eating disorders are a lifestyle preference. Eating disorders are essentially serious and often fatal illnesses that cause severe disturbances to a person's eating behaviors. Obsessions with food, body weight, and shape may also signal an eating disorder. Common eating disorders include anorexia nervosa, bulimia nervosa, and binge-eating disorder.

According to result of current study, it was concluded that both Self-Concept and Self-Handicapping play crucial roles in pathogenesis of Eating disorders. The result of current study is consistent with the result of the study conducted by Jacobi and Colleagues (2004) in which they assessed Specificity of self-concept disturbances in eating disorders. They concluded that self-concept deficits are more pronounced in eating-disordered patients but cannot be regarded as highly specific [17]. The difference between aforementioned study and current study is that in current study we assessed relationship of self-concept with respect to all subgroups of Eating disorders separately. In another study conducted by Stain and Corte (2007), they looked at content and organization of the self-concept in women with anorexia nervosa and bulimia nervosa. They concluded that Women with $(\mathrm{AN})$ and $(\mathrm{BN})$ had fewer positive and more negative and highly interrelated self-schemas compared to controls, and women with BN showed information processing evidence of a fat self-schema available in memory. These self-concept properties predicted eating disordered attitudes and behavior [18]. Brooke (2016) postulates that SelfHandicapping has mediating role in Eating disorders; the results suggest that self-handicapping may be an important link in the pathway through which ED develop [19].

\section{References}

[1] Fairburn CG, Harrison PJ. (2003). Eating disorders with and without comorbid depression and anxiety: similarities and differences in a clinical sample of children and adolescents. Available: https://www.ncbi.nlm.nih.gov/pubmed/12573387. Last accessed Dec 2017.

[2] Sim, L. A., McAlpine, D. E., Grothe, K. B., Himes, S. M., Cockerill, R. G., \& Clark, M. M. (2010). Identification and Treatment of Eating Disorders in the Primary Care Setting. Mayo Clinic Proceedings, 85(8), 746-751. http://doi.org/10.4065/mcp.2010.0070

[3] Rikani, A. A., Choudhry, Z., Choudhry, A. M., Ikram, H., Asghar, M. W., Kajal, D., Mobassarah, N. J. (2013). A critique of the literature on etiology of eating disorders. Annals of Neurosciences, 20(4), 157-161. http://doi.org/10.5214/ans.0972.7531.200409

[4] American Psychiatric Association. (4th ed). Washington,; DC.: 1994. American Psychiatry Association. Diagnostic and Statistical Manual of Mental Disorders.

[5] Hoek HW, Hoeken D. Review of the prevalence and incidence of eating disorders. International Journal of Eating Disorders. 2003;34:383-96. [PubMed] 
[6] Hudson JI, Hiripi E, Pope HG et al. The prevalence and correlates of eating disorders in the national Comorbidity survey replication. Biological psychiatry. 2007;61:348-358. [PMC free article] [PubMed].

[7] Boyce WF. Their health and well-being. Ottawa: Ontario. Health Canada; 2004. Young people in Canada.

[8] Canadian Institute for Health Information 2006: Hospital Morbidity Database.

[9] Moore R, Mao Y, Zhang J. Ottawa: Health Canada; 1997. Economic Burden of Illness in Canada, [PubMed].

[10] Sullivan P. Course and outcome of anorexia nervosa and bulimia nervosa. Eating disorders and obesity. 2002;6:226232.

[11] Seyyed Mohammad Moosavi, Department of Psychiatry, Mazandaran University of Medical Sciences, Sari, Iran Fatemeh Amini, Department of Psychology, Islamic Azad University of Sari, Sari, Iran. (2016). Role of Anxiety, Depression and Anger in Eating Disorders-Structural Model. Available: http://www.sciencepublishinggroup.com/journal/paperinfo?jo urnalid $=653 \&$ doi $=10.11648 /$ j.ajpn.20170504.11. Last accessed Dec 2017.

[12] Matilda E Nowakowski, corresponding author Traci McFarlane and Stephanie Cassin. (2013). Alexithymia and eating disorders: a critical review of the literature. Available: https://www.ncbi.nlm.nih.gov/pmc/articles/PMC4081716/. Last accessed May-2017.

[13] Casper RC. (1998). Depression and eating disorders. Available: https://www.ncbi.nlm.nih.gov/pubmed/9809221. Last accessed May-2017.

[14] Hughes EK, Goldschmidt AB, Labuschagne Z, Loeb KL, Sawyer SM, Le Grange D. (2013). Eating disorders with and without comorbid depression and anxiety: similarities and differences in a clinical sample of children and adolescents. Available: https://www.ncbi.nlm.nih.gov/pubmed/23681932. Last accessed May-2017.

[15] Michael Kyrios, Richard Moulding, Guy Doron, Sunil S. Bhar, Maja Nedeljkovic, Mario Mikulincer (2015). The Self in Understanding and Treating Psychological Disorders. United Kingdom: Cambridge University Pres. 43.

[16] Kathleen A. Martin Lawrence R. Brawley. (1999). Is the selfhandicapping scale reliable in non-academic achievement domains? Available:

http://www.sciencedirect.com/science/article/pii/S0191886999 000392. Last accessed Dec 2017.

[17] Jacobi C, Paul T, de Zwaan M, Nutzinger DO, Dahme B. (2004). Specificity of self-concept disturbances in eating disorders. Available: https://www.ncbi.nlm.nih.gov/pubmed/14994358. Last accessed Dec 2017.

[18] Stein KF, Corte C. (2007). Identity impairment and the eating disorders: content and organization of the self-concept in women with anorexia nervosa and bulimia nervosa. Available: https://www.ncbi.nlm.nih.gov/pubmed/17676674. Last accessed Dec 2017.

[19] Brooke Kelly Strumbel. (2016). The Mediating Effects of Self-handicapping on Eating Disorder Symptomatology. Available:

http://engagedscholarship.csuohio.edu/cgi/viewcontent.cgi?art icle $=1898 \&$ context=etdarchive. Last accessed Dec 2017.

[20] National Institute Of Mental Healtht. (Feb 2016). Eating Disorders with and without comorbid depression and anxiety: similarities and differences in a clinical sample of children and adolescents. Available: https://www.nimh.nih.gov/health/topics/eatingdisorders/index.shtml. Last accessed Dec 2017. 